\title{
Lessons Learned in the Implementation of Remote Telehealth Care in College Psychiatry
}

\author{
Paul Quinlan ${ }^{1}$ (D) $\cdot$ Rebecca Smith ${ }^{1} \cdot$ Nora Feldpausch $^{1,2} \cdot$ Leigh White $^{1}$ \\ Received: 6 December 2020 / Accepted: 18 February 2021 / Published online: 25 March 2021 \\ (C) Academic Psychiatry 2021
}

To the Editor:

The impact of COVID-19 in the USA by early March 2020 led state governments to institute stay-at-home orders, disrupting outpatient psychiatric care. Telehealth rapidly gained popularity as a means for psychiatric treatment continuity. Telehealth describes providing care to the patient by electronic means such as by telephone or videoconferencing [1]. The authors, psychiatrists at Michigan State University Counseling and Psychiatric Services (MSU CAPS), a part of MSU Student Health and Wellness, share in this letter the rapid implementation of telehealth at their academic institution and its substitution for previous care. The psychiatric practice at MSU CAPS consisted of in-person evaluations and follow-up medication management utilizing an electronic health record (EHR). During their matriculation, MSU students may be located on the central campus as well as various locations across the globe. The timing of the COVID-19 pandemic fell just after the university's spring break, when on March 11, 2020, MSU shifted to online courses preceding a state government order to remain at home [2]. Following the move to online courses, the majority of MSU students departed campus for their homes in Michigan and other localities. The MSU CAPS psychiatric service, operating at peak demand at this time of the semester, needed to accommodate existing and new appointments as both patients and providers relocated off campus. A MSU business agreement allowed the psychiatrists access to a Zoom application compliant with the Health Insurance Portability and Accountability Act (HIPAA) on service-assigned tablets along with the EHR. The initial challenge was to shift all psychiatric care to remote telehealth as soon as possible.

Paul Quinlan

quinlan6@msu.edu

1 Michigan State University, East Lansing, MI, USA

2 Mantra Health, New York, NY, USA
The requirement of MSU CAPS providers to remain at home necessitated an immediate switch to telephone contact as the first phase of implementing telehealth. Within 10 days of starting remote care, psychiatry shifted to HIPAAcompliant Zoom appointments for patient encounters. The role of support staff in this transition proved critical. To implement check-in, support staff contacted the student by phone a few minutes before the scheduled Zoom appointment, confirming password access and availability. Pairing with a support staff ensured the psychiatrist knew whom to contact for questions related to a scheduled appointment or to report a missed appointment needing to be rescheduled. A secure group-texting application within the EHR allowed support staff to rotate in and out, providing constant monitoring of the scheduled cases. A nurse or medical assistant also included in the team initially contacted a new patient for the scheduled initial evaluation to complete health history screening, review of systems, and medication reconciliation and to provide updates via this secure-text EHR application to the psychiatrist. Although increasing allocated time for initial evaluations and follow-up appointments to adapt to the new mode of care returned to previous durations, many students still required extra time. Some were isolated at residences in and around MSU due to inability to travel. Health care needs and resources for food and housing issues as well as seeking guidance in accessing therapy became the new priority. Psychiatrists referred students to counselors at MSU CAPS who provided triage and counseling via phone or Zoom.

The outcome of this transition to telehealth maintained the availability of psychiatric care to current and new patients. If a student could not access Zoom due to Internet or network limitations at the time of the appointment, the psychiatrist called the student's phone. Psychiatrists utilized an application on their cell phones so students received the call listing the Caller ID as MSU CAPS to prevent unrecognized numbers from being blocked. For some students, the Internet was the only available method of communication. In these cases, the patient received a secure message with the Zoom meeting 
address via the EHR portal messaging service. The 2020 summer semester saw a $25 \%$ increase in psychiatric care compared to the previous year's psychiatry schedule. Telehealth continued for the summer and fall semesters of 2020 for all psychiatric care for MSU CAPS students. Maintaining care to out-of-state students created a challenge for the psychiatrists. As of May 5, 2020, nearly all US states and territories established a plan for temporary practice by out-of-state providers, allowing ongoing care for their residents via telehealth [3]. Individual pharmacies in some states would not dispense Schedule IIc prescriptions from the MSU psychiatrists, instead requiring a provider licensed in their state to prescribe. MSU CAPS psychiatrists regularly consulted with the university's legal counsel to better understand and work within current prescribing laws established in each state. MSU's international students trapped outside of the USA by early travel bans struggled with running out of medication in the subsequent months of travel restriction. Providers guided students on accessing their EHR visit summaries in the portal to share information with local health care providers who bridged their care. As these restrictions eased, students returned, but the university saw a reduction in international students registered for the fall semester of 2020. Some students declined telehealth services after leaving campus in spring 2020. Some students remaining at home were reluctant to continue via telehealth because family members might discover that they were receiving mental health services. It was not feasible to communicate with these students via the EHR portal due to the lack of real-time communication. In these circumstances, students adapted to remotely connecting from inside their cars to ensure privacy. Some chose to wait to follow up upon returning to MSU in the fall 2020 semester. MSU administration allowed a limited number of students to return to the MSU campus housing for this reason.
The MSU CAPS psychiatrists observed the pandemic caused some students to minimize their stress severity in appointments. Active listening, comparison with previously reported history, and the use of established depression and anxiety screening tools helped students disclose the challenges they faced during the pandemic.

As many US colleges and universities attempt to continue in-person classes, the impact of COVID-19 may require these institutions to shift to telehealth-based patient care. These lessons shared offer other institutions and their academic psychiatrist strategies for successful implementation of telehealth in their student patient population.

\section{Declarations}

Disclosures On behalf of all authors, the corresponding author states that there is no conflict of interest.

\section{References}

1. United States Government. What is telehealth? How is telehealth different from telemedicine? [Internet]. The Office of the National Coordinator for Health Information Technology 2020. [cited 2020 Jan 31]. https://www.healthit.gov/faq/what-telehealth-howtelehealth-different-telemedicine

2. The Office of the Governor Gretchen Whitmer Executive Order 2020-42 (COVID-19) State of Michigan Website 2020. [cited 2021 Jan 31]. https://www.michigan.gov/whitmer/0,9309,7-387-90499_ 90705-525182\%2D\%2D,00.html

3. Federation of State Medical Boards. U.S. states and territories modifying requirements for telehealth in response to COVID-19. [Internet] www.fsmb.org 2020. [cited 2021 Jan 31]. https://www. fsmb.org/siteassets/advocacy/pdf/states-waiving-licensurerequirements-for-telehealth-in-response-to-covid-19.pdf

Publisher's Note Springer Nature remains neutral with regard to jurisdictional claims in published maps and institutional affiliations. 